\title{
Risk of upper gastrointestinal adverse events in Malaysian rheumatic patients on long-term non-steroidal anti- inflammatory drugs
}

\begin{abstract}
Background: Non-steroidal anti-inflammatory drug (NSAID)-induced upper gastrointestinal (GI) adverse events are well-described in the Western population but data is lacking in Asian patients. This study aims to describe the incidence and predictive factors for NSAID-induced upper GI complications in a cohort of multi-ethnic patients in Malaysia.
\end{abstract}

Methods and Findings: A retrospective cohort study was conducted in adult patients with rheumatoid arthritis (RA) and/or osteoarthritis (OA) from 2010-2013 in four main rheumatology centres in Malaysia with computerized clinical and pharmaceutical records. Clinical, pharmaceutical and demographic data over a 24-months follow-up period were analysed in subjects who were prescribed long-term NSAID therapy (defined as a minimum duration of four weeks). 634 patients were included in the final analysis with the following characteristics: mean age $53.4 \pm 12.5$ years, $89.9 \%$ female, diagnosis: RA $59.5 \%$, OA $10.2 \%$ and RA/OA combination 30.3\%. 371 (58.5\%) patients received non-selective NSAIDs and 263 (41.5\%) patients received COX-2 inhibitors. There were a total of $84 \mathrm{Gl}$ adverse events during the period of study, giving an incidence rate of 66.2 per 1000 person-years and a risk of $13.2 \%$. The majority of upper GI adverse events was dyspepsia (92.9\%), and only $7.1 \%$ with peptic ulcer disease/ upper GI bleeding Multivariate analysis showed that the only independent predictive factor of upper Gl adverse event in this cohort was a history of upper GI disease (O.R. 2.073, 95\% C.I. 1.029 - 4.176). COX-2 inhibitor showed a trend towards, but not independently predictive of, GI protection in this analysis (OR $0.643 ; 95 \%$ C.I $0.397-1.043)$.

Conclusion: Malaysian rheumatic patients on long-term NSAID therapy, managed at referral centres, have a $13.2 \%$ risk of upper $\mathrm{Gl}$ adverse events, with dyspepsia being the commonest complication. Patients with a history of upper GI disease were twice as likely to develop further upper GI adverse events with the use of long-term NSAIDs.

Keywords: gastrointestinal $•$ osteoarthritis $\bullet$ rheumatoid arthritis $\bullet$ non-steroidal anti-inflammatory drugs

Abbreviations: ARAMIS- Arthritis, Rheumatism and Aging Medical Information System; CLASS-Celecoxib Long-term Arthritis Safety Study; Gl- Gastrointestinal; H2RA- Histamine2 Receptor Antagonist; NSAIDNon-steroidal Anti-inflammatory Drug; OA- Osteoarthritis; PPI- Proton Pump Inhibitor; PUD- Peptic Ulcer Disease; RA- Rheumatoid Arthritis; SPSS- Statistical Package for the Social Science; SUCCESS-I- Successive Celecoxib Efficacy and Safety Study I; TARGET- Therapeutic Arthritis Research and Gastrointestinal Event Trial; UGIB- Upper Gastrointestinal Bleeding

\section{Introduction}

Non-steroidal anti-inflammatory drugs (NSAIDs) are one of the most commonly used medications worldwide [1,2]. More than 30 million NSAIDs are prescribed every day in the United States [2] and they are also widely available as an over-the-counter medication. The efficacies of their anti-inflammatory and analgesic effects are well-established [3] and NSAIDs are recommended in the management of rheumatic diseases such as rheumatoid arthritis (RA) [4] and osteoarthritis (OA) [5-7].

Despite the recognised benefits and availability of NSAIDs, they are also known to cause

\author{
Lydia Say Lee Pok ${ }^{* 1}$, Fatiha \\ Hana Shabaruddin², \\ Maznah Dahlui ${ }^{3}$, Sargunan \\ Sockalingam', Mohd Shahrir \\ Said ${ }^{4}$, Azmillah Rosman ${ }^{5}$, \\ Ing-Soo Lau' ${ }^{5}$, Liza Mohd Isa ${ }^{6}$, \\ Heselynn Hussein ${ }^{6}$, Chin Teck \\ $\mathbf{N g}^{7,8}$ \& Sanjiv Mahadeva ${ }^{1}$ \\ 'Department of Medicine, Faculty of \\ Medicine, University of Malaya, Malaysia \\ ${ }^{2}$ Department of Pharmacy, Faculty of \\ Medicine, University of Malaya, Malaysia \\ ${ }^{3}$ Department of Social and Preventive \\ Medicine, Faculty of Medicine, University \\ of Malaya, Malaysia \\ ${ }^{4}$ Department of Medicine, Faculty of \\ Medicine, University Kebangsaan Malaysia \\ Malaysia \\ ${ }^{5}$ Department of Medicine, Selayang \\ Hospital, Malaysia \\ ${ }^{6}$ Department of Medicine, Putrajaya \\ Hospital, Malaysia \\ 7Department of Rheumatology and \\ Immunology, Singapore General Hospital, \\ Malaysia \\ 8/-NUS Medical School, Singapore \\ *Author for correspondence: \\ lydiapok@gmail.com
}


a spectrum of adverse events involving the gastrointestinal (GI), cardiovascular and renal systems. The most common of these adverse events are gastrointestinal, with a reported prevalence of $15-36.7 \%$ for dyspepsia [8-10], 4.36-6.19\% for peptic ulcer disease (PUD) [11] and $0.21-3.6 \%$ for upper GI bleeding (UGIB) $[11,12]$. These adverse events have important clinical implications, contributing to patient morbidity, mortality and increased healthcare utilisation and costs.

One of the strategies to limit these adverse events includes identifying predictive factors for these adverse events among long-term NSAID users. Established GI risk factors include age $\geq 65$ years [13], upper GI history [14], concomitant medications (e.g. prednisone, aspirin, nonaspirin anti-platelet and anticoagulant) $[15,16]$ and $H$. pylori infection [17]. It is crucial for the prescribing clinician to identify high-risk patients, in whom specific options can be clinically beneficial and cost-effective, such as prescribing more GI-favourable COX-2 specific inhibitor versus traditional NSAID, adding a GI protective agent (e.g. proton pump inhibitor) or avoiding NSAIDs altogether. There is a paucity of information in Asian patients on long-term NSAID therapy. A previous community-based survey in Malaysia has revealed that over-thecounter purchases for NSAIDs for prolonged duration were not uncommon [18]. Another study from Northern Malaysia revealed that 35,944 prescriptions for NSAIDs per 100,000 patients were administered annually from a single institution [19], indicating the common usage of NSAIDs among Asians.

As NSAIDs are commonly prescribed on a long-term basis for patients with chronic rheumatological conditions, this study aimed to identify the incidence and predictive factors of NSAID-induced upper GI adverse events in Malaysian patients with chronic rheumatic diseases.

\section{Methods}

\section{Study population}

A retrospective, multi-centre, cohort study was conducted at four large public hospitals with rheumatology units in the Klang Valley, an area with the highest population density in Malaysia of almost 7 million people [20].

\section{Study protocol}

Electronic prescription data in the respective hospitals were accessed to determine long-term NSAID users (defined as at least four weeks prescriptions of any type of NSAID) among patients diagnosed with RA and/or OA who were on active rheumatology clinic follow up in 2010 or 2011 in the four hospitals. These patients were followed up for 24 months via manual review of the medical records to determine whether any upper GI adverse event(s) developed in the 24 months follow up period. The exclusion criteria were incomplete prescription data, patients who defaulted follow-up and GI adverse event within 6 months prior to recruitment in the study.

\section{Data collection}

A retrospective, multi-centre, cohort study was conducted at four large public hospitals with rheumatology units in the Klang Valley, an area with the highest population density in Malaysia of almost 7 million people [20].

Data analysis

Data was analysed using the Statistical Package of Social Sciences (SPSS) version 23. Descriptive statistics was used for demographic data analysis and frequencies of each type of GI adverse events. The incidence rate (per 1000 person-years) was calculated using the formula $=$ (number of new cases of upper GI adverse events $\times 1000) /($ total number of RA/OA patients observed $\times 2$ years of observation). Each concomitant medication (prednisone, aspirin, non-aspirin anti-platelet and anticoagulant) was considered an individual GI risk factor (one point each) in the analysis. Pearson chi-square test was used to determine significant associations for categorical variables with a p-value of $<0.05$ indicating statistical significance. The odds ratio for the calculation of risk of upper GI events was determined using logistic regression for the multivariate test.

\section{Results}

1679 patients with an RA and/or OA diagnosis on regular rheumatology clinic follow up in 2010 or 2011 at the four hospitals were screened. 634 of these patients received long-term NSAID therapy and the medical records of these patients were followed up for 24 months from the date of the NSAID prescription.

\section{Demographic data}

The demographic data of the included patients $(\mathrm{N}=634)$ are described in Table 1 . Their mean age was $53.4 \pm 12.5$ years and the majority of patients $(83.0 \%)$ were under the age of 65 years. Most patients were female (89.9\%). Almost half 


\begin{tabular}{|c|c|}
\hline Demographic data & Number (\%) (N=634) \\
\hline \multicolumn{2}{|l|}{ Patients from each centre } \\
\hline UMMC & $201(31.7 \%)$ \\
\hline HUKM & $92(14.5 \%)$ \\
\hline Selayang Hospital & $141(22.2 \%)$ \\
\hline Putrajaya Hospital & 200 (31.6\%) \\
\hline \multicolumn{2}{|l|}{ Age } \\
\hline Mean \pm SD (years) & $53.4 \pm 12.5$ \\
\hline \multicolumn{2}{|l|}{ Age group } \\
\hline Non-elderly (<65 years) & $526(83.0 \%)$ \\
\hline Elderly ( $\geq 65$ years) & $108(17.0 \%)$ \\
\hline \multicolumn{2}{|l|}{ Sex } \\
\hline Male & $64(10.1 \%)$ \\
\hline Female & $570(89.9 \%)$ \\
\hline \multicolumn{2}{|l|}{ Race } \\
\hline Malay & 253 (39.9\%) \\
\hline Chinese & $168(26.5 \%)$ \\
\hline Indian & 202 (31.9\%) \\
\hline Others & $11(1.7 \%)$ \\
\hline \multicolumn{2}{|l|}{ Rheumatic disease } \\
\hline Rheumatoid arthritis (RA) & 377 (59.5\%) \\
\hline Osteoarthritis (OA) & $65(10.3 \%)$ \\
\hline $\mathrm{RA}$ and $\mathrm{OA}$ & $192(30.3 \%)$ \\
\hline \multicolumn{2}{|c|}{ Gastrointestinal (GI) history } \\
\hline No GI disease & $561(88.5 \%)$ \\
\hline Dyspepsia & $64(10.1 \%)$ \\
\hline Peptic ulcer disease & $9(1.4 \%)$ \\
\hline \multicolumn{2}{|l|}{ Concomitant medications } \\
\hline Prednisone & $286(45.1 \%)$ \\
\hline Aspirin & $53(8.4 \%)$ \\
\hline $\begin{array}{l}\text { Other antiplatelets } \\
\text { (Clopidogrel, Ticlopidine) }\end{array}$ & $11(1.7 \%)$ \\
\hline Anticoagulant & $8(1.3 \%)$ \\
\hline \multicolumn{2}{|l|}{ No. of GI risk factors* } \\
\hline 0 & $217(34.2 \%)$ \\
\hline 1 & 311 (49.0\%) \\
\hline 2 & $91(14.4 \%)$ \\
\hline 3 & $14(2.2 \%)$ \\
\hline 4 & $1(0.2 \%)$ \\
\hline \multicolumn{2}{|c|}{ Concomitant GI prophylaxis } \\
\hline Yes & 234 (36.9\%) \\
\hline \multicolumn{2}{|l|}{ Co-morbidities } \\
\hline Diabetes mellitus & $111(17.5 \%)$ \\
\hline Hypertension & $260(41.0 \%)$ \\
\hline Dyslipidaemia & $232(36.6 \%)$ \\
\hline Ischaemic heart disease & $22(3.5 \%)$ \\
\hline Chronic kidney disease & $2(0.3 \%)$ \\
\hline \multicolumn{2}{|c|}{$\begin{array}{l}\text { *Established GI risk factors [7-10]: age } \geq 65 \text { years, upper } \\
\text { GI history, concomitant medications (prednisone, } \\
\text { aspirin, non-aspirin anti-platelet and anticoagulant } \\
\text { [one point for each concomitant medication]). UMMC, } \\
\text { University of Malaya Medical Centre; HUKM, Hospital } \\
\text { Universiti Kebangsaan Malaysia. }\end{array}$} \\
\hline
\end{tabular}

of the patients (45.1\%) were on concomitant prednisone, while aspirin was concomitantly prescribed in only $8.1 \%$ of patients. A small proportion of patients were on other antiplatelet agents (1.7\%) and anticoagulants (1.3\%). 88.5\% of patients had no history of upper GI disease and there were no patients with a history of upper gastrointestinal bleeding. We determined that $371(58.5 \%)$ of the 634 patients received NSAIDs prior to the start of the 24 months follow-up in this study. There were 371 (58.5\%) patients in the non-selective NSAIDs group, comprising of 267 patients who received nonselective NSAIDs and 104 patients who received combination of non-selective and COX-2 inhibitors. $263(41.5 \%)$ patients were prescribed only COX-2 inhibitors.

\section{Incidence of upper $\mathrm{Gl}$ adverse events}

A total of 84 upper GI adverse events occurred during the 24 months follow up, translating to an incidence of 66.2 per 1000 person-years and a risk of $13.2 \%$. These upper GI adverse events consisted of 78 patients with dyspepsia, five patients with PUD and one patient with upper GI bleeding.

Upper GI adverse events were higher in the COX-2 group (43/263, 16.3\%) compared to the non-selective NSAID group $(41 / 371,11.1 \%)$ but this did not reach statistical significance (Chi-square $\mathrm{p}=0.053) .16(39.0 \%)$ of the 41 patients with upper GI adverse events in the non-selective NSAID group took a combination of selective and non-selective NSAIDs in the 24 months follow up period.

\section{Predictive factors of upper $\mathrm{Gl}$ adverse events}

Univariate analysis Table 2 revealed that variables that were associated with upper GI adverse events were a gastrointestinal history, number of GI risk factors (0 and 1-2 risk factors) and GI prophylaxis. The type of NSAID, 3-4 GI risk factors and concomitant prednisone did not reach statistical significance in this analysis. Age group and concomitant aspirin were not associated with upper GI adverse events. There was no significant difference in upper GI adverse events when comparing the type of rheumatic disease (RA/RA with OA vs. OA alone).

Multivariate analysis, analysed using logistic regression analysis Table 3, subsequently revealed that a previous history of upper GI disease (OR 2.073, 95\% C.I. 1.029- 4.176) was independently predictive of GI adverse event. Gender (male), concomitant prednisone and GI 
Table 2. Univariate analysis of variables associated with upper GI adverse event.

\begin{tabular}{|l|c|c|c|} 
Variable & $\begin{array}{c}\text { No adverse } \\
\text { events }\end{array}$ & $\begin{array}{c}\text { Adverse } \\
\text { event }\end{array}$ & p-value \\
\cline { 1 - 3 } Age $>\mathbf{6 5}$ & \multicolumn{3}{|l|}{} \\
\cline { 1 - 2 } & $456(86.7 \%)$ & $70(13.3 \%)$ & \multirow{2}{*}{0.923} \\
\hline Yes & $94(87.0 \%)$ & $14(13.0 \%)$ & \\
\cline { 1 - 2 } & &
\end{tabular}

\section{Sex: Male}

\begin{tabular}{|l|c|c|c|}
\hline No & $490(86.0 \%)$ & $80(14.0 \%)$ & \multirow{2}{*}{0.082} \\
\cline { 1 - 3 } Yes & $60(93.7 \%)$ & $4(6.3 \%)$ & \\
\cline { 1 - 3 }
\end{tabular}

Disease

\begin{tabular}{|l|l|l|l|}
\hline $\begin{array}{l}\text { RA / RA with } \\
\text { OA }\end{array}$ & $495(87.0 \%)$ & $74(13.0 \%)$ & 0.592 \\
\hline OA & & & \\
\hline
\end{tabular}

\begin{tabular}{|l|c|c|c|}
\hline OA & $55(84.6 \%)$ & $10(15.4 \%)$ & \\
\hline GI history & \multicolumn{3}{|c|}{} \\
\cline { 1 - 3 } No & $497(88.6 \%)$ & $64(11.4 \%)$ & \multirow{2}{*}{$<.001$} \\
\hline Yes & $53(72.6 \%)$ & $20(27.4 \%)$ & \\
\cline { 1 - 3 }
\end{tabular}

Number of GI risk factors

\begin{tabular}{|l|c|c|c|}
\hline 0 & $199(91.7 \%)$ & $18(8.3 \%)$ & 0.006 \\
\hline 1 or 2 & $341(84.8 \%)$ & $61(15.2 \%)$ & 0.004 \\
\hline 3 or 4 & $10(66.7 \%)$ & $5(33.3 \%)$ & 0.069 \\
\hline Prednisone & \multicolumn{3}{|l}{} \\
\hline No & $310(89.1 \%)$ & $38(10.9 \%)$ & \multirow{2}{*}{0.056} \\
\hline Yes & $240(83.9 \%)$ & $46(16.1 \%)$ & \\
\hline
\end{tabular}

\begin{tabular}{|l|c|c|c|}
\hline Aspirin \\
\cline { 1 - 3 } No & $504(86.7 \%)$ & $77(13.3 \%)$ & \multirow{2}{*}{0.993} \\
\cline { 1 - 3 } Yes & $46(86.8 \%)$ & $7(13.2 \%)$ & \\
\hline
\end{tabular}

\begin{tabular}{|l|l|l|l|}
\hline \multicolumn{3}{|l|}{ Type of NSAID } \\
\cline { 1 - 3 } Non-selective & $330(88.9 \%)$ & $41(11.1 \%)$ & \multirow{2}{*}{0.053} \\
\hline COX-2 & $220(83.7 \%)$ & $43(16.3 \%)$ & \\
\cline { 1 - 3 }
\end{tabular}

Number of NSAIDs

\begin{tabular}{|c|c|c|c|}
\hline 1 & 438 (87.8\%) & $61(12.2 \%)$ & \multirow{2}{*}{0.143} \\
\hline$>1$ & $112(83.0 \%)$ & $23(17.0 \%)$ & \\
\hline \multicolumn{4}{|c|}{ GI prophylaxis } \\
\hline No & 357 (89.3\%) & $43(10.7 \%)$ & \multirow{2}{*}{0.015} \\
\hline Yes & $193(82.5 \%)$ & 41 (17.5\%) & \\
\hline
\end{tabular}

Other antiplatelet (Ticlopidine and Clopidogrel)

\begin{tabular}{|l|c|c|c|}
\cline { 1 - 3 } No & $545(87.5 \%)$ & $78(12.5 \%)$ & \multirow{2}{*}{0.001} \\
\cline { 1 - 3 } Yes & $5(45.5 \%)$ & $6(54.5 \%)$ & \\
\cline { 1 - 2 }
\end{tabular}

\section{Anticoagulation}

\begin{tabular}{|l|c|c|c|}
\hline No & $543(86.7 \%)$ & $83(13.3 \%)$ & \multirow{2}{*}{0.949} \\
\cline { 1 - 3 } Yes & $7(87.5 \%)$ & $1(12.5 \%)$ & \\
\cline { 1 - 1 } $\begin{array}{l}\text { Gl, gastrointestinal; RA, rheumatoid arthritis; OA, } \\
\text { osteoarthritis; NSAID, non-steroidal anti-inflammatory } \\
\text { drug }\end{array}$ \\
\hline
\end{tabular}

prophylaxis were not independent predictors in this analysis. The number of GI risk factors was also not an independent predictor as this did not reach statistical significance although there was a trend towards higher risk of GI adverse events with increasing number of GI risk factors. COX-2 inhibitor showed a trend towards, but not independently predictive of, GI protection in this analysis (OR 0.643; 95\% C.I. 0.3971.043).

\section{Discussion}

This study has described the incidence and predictive factors of NSAID-induced upper GI adverse events in Malaysian patients with $\mathrm{RA}$ and $\mathrm{OA}$. The incidence rate was $66.2 \mathrm{per}$ 1000 person-years and dyspepsia was the most common adverse effect. The risk of upper GI adverse events found in this study (13.2\%) is similar to a North America study of 1921 patients with RA from the ARAMIS (Arthritis, Rheumatism and Aging Medical Information System) centres, which reported a risk of $15 \%$.

\section{Predictive factors of upper Gl adverse events}

Among the various recognised risk factors for GI adverse events in long-term NSAID users, only a prior history of GI disease was identified as an independent predictive factor in this study. A previous meta-analysis demonstrated that a prior history of complicated or uncomplicated ulcers (pooled RR 15.4 [95\% CI 12.6-18.9] and RR 5.9 [95\% CI 5.2-6.7] respectively) [21] was a strong predictor of risk of GI events. A large, prospective, double-blinded GI outcomes trial of 8076 patients with rheumatoid arthritis additionally reported that a history of GI disease increases the risk of GI events by approximately 2- to 4-fold [14]. Furthermore, patients with prior history of NSAID-related dyspepsia have been reported to have an increased risk of ulcer complications (OR 8.7, 95\% CI 4.0-18.9) when consuming long-term NSAIDs [22]. However, we are not able to determine whether prior history of NSAID-related dyspepsia was a predictor of upper GI events as the aetiology of prior upper GI disease was not available from the patient's medical records.

Other factors, such as concomitant usage of antiplatelet agents [15,23,24], anti-coagulants [2527] and steroids [16,28,29] have been shown to increase the risk of NSAID-associated GI complications but these factors were not found to be predictive in this study. We were not able to explore the role of Helicobacter pylori infection 


\begin{tabular}{|l}
\begin{tabular}{|l|c|c|c|}
\hline \multicolumn{1}{|c|}{\begin{tabular}{c} 
Table 3. Multivariate analysis of independent predictive factors of upper Gl adverse event. \\
\hline Variable
\end{tabular}} & Odds ratio & $\mathbf{9 5 \%}$ C.I. & p-value \\
\hline Sex (Male) & 2.192 & $0.764-6.287$ & 0.144 \\
\hline Gastrointestinal history & 2.073 & $1.029-4.176$ & 0.041 \\
\hline Prednisone & 1.402 & $0.740-2.665$ & 0.3 \\
\hline Gl prophylaxis & 1.331 & $0.805-2.200$ & 0.265 \\
\hline No. of Gl risk factors 1-2 & 1.328 & $0.613-2.878$ & 0.472 \\
\hline No. of Gl risk factors 3-4 & 1.979 & $0.447-8.752$ & 0.368 \\
\hline Type of NSAID COX-2 inhibitor & 0.643 & $0.397-1.043$ & 0.074 \\
\hline
\end{tabular}
\end{tabular}

[17,30] or higher doses of NSAIDs [2,31] and multiple NSAID use [28], which are recognised causes of NSAID-associated GI complications as this information was not available for all patients in this study.

Although each GI risk factor has different odds or risk ratio for GI adverse events, there is no widely accepted algorithm to aid in quantifying and combining multiple risk factors for upper GI adverse events due to NSAIDs. However, a large randomised double-blinded study of over 34,000 patients [13] showed that the rate of GI events increased with increasing number $(0,1,2,3$ and 4) of the four major risk factors (age $\geq 65$ years, prior upper GI clinical event, low-dose aspirin use and systemic corticosteroid use). In this study, we combined the number of risk factors in our study into groups of increasing numbers for analysis (0, 1-2 and 3-4 risk factors).

\section{Limitations and Strengths}

One of the limitations of this retrospective study was the complete reliance on medical records and as such, some patients may not have reported their GI symptoms during routine clinic visits, thus affecting the true incidence of GI adverse events in this patient population and subsequently further analysis on the predictive factors. Secondly, patients with GI risk factor(s) may have been preferentially prescribed a COX-2 inhibitor or GI prophylaxis, potentially confounding the results of this study. Additionally, only double-dose H2RAs have been shown to reduce upper GI adverse events [9,32] and all patients prescribed with H2RAs for GI prophylaxis in this study were given standard doses of H2RAs. Another possible confounder is over-the-counter usage of NSAID, which is common among Malaysian adults [18]. It is possible that rheumatic patients prescribed COX-2 inhibitors alone may have additionally consumed non-selective NSAID by purchasing over-the-counter medications. Similarly, our data on patients using GI protective agents may have been inaccurate, as over-the-counter availability and usage of H2RAs and PPIs are also quite common in the local community [33]. Another limitation was the fact that this study was not sufficiently powered to calculate for differences in GI adverse events between classes of NSAID. This may be the reason why COX-2 inhibitors did not significantly confer protection in this study whereas several large randomised clinical trials (CLASS, TARGET and SUCCESS-I) $[10,34,35]$ have shown otherwise. For possibly the same reason, GI prophylaxis was not found to be protective in this study, in contrast to the findings of other large studies $[32,36]$.

The data in this study is robust for several reasons. Firstly, the upper GI effects in this study have been observed in a uniform group of patients (i.e. patients with rheumatic diseases) and there are unlikely to be other confounders for GI complications in these patients apart from their concomitant treatment for the rheumatic diseases. However, we acknowledge that other minor confounders such as diet, short-term medications (e.g. antibiotics) and alcohol history may have existed. Secondly, the study subjects were fairly representative of most Malaysian patients with rheumatic diseases as the public healthcare system in Malaysia manages the majority of adults with complex, chronic diseases. The Malaysian healthcare system is generally divided into public and privately funded health institutions [37]. Nationally, patients mostly rely on the publicly-funded healthcare system for the management of complex chronic disease. Due to the chronic and costly treatment of rheumatology disorders, particularly RA that often has relatively early onset and peaking at age 30-55 years old [38], it is estimated that the majority of rheumatology patients in Malaysia are treated within the public healthcare system. Furthermore, there was comprehensive data on all medication prescriptions as this was available electronically in all four centres. Our data may not be representative of patients on longterm NSAID managed in non-referral centres. Nevertheless, this study provides useful clinical 
information for patients managed in tertiary care referral centres.

\section{Conclusion}

The risk of upper GI adverse events in our Malaysian cohort of patients (13.2\%) is comparable to the Western population. Prior upper GI disease was the only independent predictive factor identified in this study and the rheumatic patients on long-term NSAIDs with this risk factor were twice as likely to develop further upper GI events. Judicious prescription of NSAIDs in patients with this risk factor is recommended. Future studies that are adequately-powered, suitably-designed and incorporate rheumatology patients in nonreferral centres and primary care are needed to determine the role of COX-2 selective inhibitors and GI protective agents in Asian patients in reducing the risk of upper GI adverse events in Asian patients on long-term NSAID.

Ethics approval

Ethical approval was granted to conduct this research within the following centres:

- University Malaya Medical Centre (Medical Ethics Committee of UMMC, MREC ID 1087.46)

- Selayang Hospital and Putrajaya Hospital (Medical Research \& Ethics Committee of the Ministry of Health Malaysia, NMRR-14-1659-23298)

- National University of Malaysia (Research Ethics Committee of the National University of Malaysia, UKM 1.5.3.5./244/FF-2015-054)

Competing and conflicting interests

All authors have no competing and conflicting interests to declare.

Funding

This study received an Investigator Initiated Research Grant from Pfizer Pharmaceuticals, no. WI194385

\section{References}

1. Breivik H, Collett B, Ventafridda V et al. Survey of chronic pain in Europe: prevalence, impact on daily life, and treatment. Eur. J. Pain. 10(4), 287-333 (2006).

2. Singh G. Gastrointestinal complications of prescription and over-the-counter nonsteroidal anti-inflammatory drugs: a view from the ARAMIS database. Arthritis, Rheumatism, and Aging Medical Information System. Am. J. Ther. 7(2), 115-21 (2000).

3. Bjordal JM, Ljunggren AE, Klovning A et al. Nonsteroidal anti-inflammatory drugs, including cyclooxygenase-2 inhibitors, in osteoarthritic knee pain: meta- analysis of randomised placebo controlled trials. $B M J$. 329(7478), 1317 (2004)

4. Luqmani R, Hennell S, Estrach C et al. British Society for Rheumatology and British Health Professionals in Rheumatology guideline for the management of rheumatoid arthritis (after the first 2 years). Rheumatology (Oxford). 48(4), 436-9 (2009).

5. Hochberg MC, Altman RD, April KT et al. American College of Rheumatology 2012 recommendations for the use of nonpharmacologic and pharmacologic therapies in osteoarthritis of the hand, hip, and knee. Arthritis. Care. Res (Hoboken). 64(4), 465-74 (2012).

6. Zhang W, Doherty M, Arden N et al. EULAR evidence based recommendations for the management of hip osteoarthritis: report of a task force of the EULAR Standing Committee for International Clinical Studies Including Therapeutics (ESCISIT). Ann. Rheum. Dis. 64(5), 669-81 (2005)

7. Zhang W, Moskowitz RW, Nuki G et al. OARSI recommendations for the management of hip and knee osteoarthritis, Part II: OARSI evidence-based, expert consensus guidelines. Osteoarthritis. Cartilage. 16(2), 137-62 (2008).

8. Larkai EN, Smith JL, Lidsky MD et al. Dyspepsia in NSAID users: the size of the problem. J. Clin. Gastroenterol. 11(2), 158-62 (1989).

9. Singh G, Ramey DR, Morfeld D et al. Gastrointestinal tract complications of nonsteroidal anti-inflammatory drug treatment in rheumatoid arthritis. A prospective observational cohort study. Arch. Intern. Med. 156(14), 1530-6 (1996).

10. Silverstein FE, Faich G, Goldstein JL et al. Gastrointestinal toxicity with celecoxib vs. nonsteroidal anti-inflammatory drugs for osteoarthritis and rheumatoid arthritis: the CLASS study: A randomized controlled trial. Celecoxib Long-term Arthritis Safety Study. JAMA. 284(10), $1247-55$ (2000).

11. Rostom A, Muir K, Dube C et al. Gastrointestinal safety of cyclooxygenase- 2 inhibitors: a Cochrane Collaboration systematic review. Clin. Gastroenterol. Hepatol. 5(7), 818-28 (2007).

12. Chan FK, Lanas A, Scheiman J et al. Celecoxib versus omeprazole and diclofenac in patients with osteoarthritis and rheumatoid arthritis (CONDOR): a randomised trial. Lancet. 376(9736), 173-9 (2010).

13. Laine L, Curtis SP, Cryer B et al. Risk factors for NSAIDassociated upper GI clinical events in a long-term prospective study of 34701 arthritis patients. Aliment. Pharmacol. Ther. 32(10), 1240-8 (2010).

14. Laine L, Bombardier C, Hawkey CJ et al. Stratifying the risk of NSAID-related upper gastrointestinal clinical events: results of a double-blind outcomes study in patients with rheumatoid arthritis. Gastroenterology. 123(4), 1006-12 (2002)

15. Dubois RW, Melmed GY, Henning JM et al. Risk of Upper Gastrointestinal Injury and Events in Patients Treated With Cyclooxygenase (COX)-1/COX-2 Nonsteroidal Antiinflammatory Drugs (NSAIDs), COX2 Selective NSAIDs, and Gastroprotective Cotherapy: An Appraisal of the Literature. J. Clin. Rheumatol. 10(4), 178-89 (2004). 
16. Piper JM, Ray WA, Daugherty JR et al. Corticosteroid use and peptic ulcer disease: role of nonsteroidal antiinflammatory drugs. Ann. Intern. Med. 114(9), 735-40 (1991).

17. Huang JQ, Sridhar S, Hunt RH. Role of Helicobacter pylori infection and non-steroidal anti-inflammatory drugs in peptic-ulcer disease: a meta-analysis. Lancet. 359(9300), 14-22 (2002).

18. Chua SS, Paraidathathu T. Utilisation of non-steroidal anti-inflammatory drugs (NSAIDs) through community pharmacies in Malaysia. Asia. Pac. J. Public. Health. 17(2), 117-23 (2005)

19. Dhabali AA, Awang R, Hamdan Z et al. Associations between prescribing nonsteroidal anti-inflammatory drugs and the potential prescription-related problems in a primary care setting. Int. J. Clin. Pharmacol. Ther. 50(12), 851-61 (2012).

20. Department of Statistics M. Population and Demography 2017, 6 March 2018.

21. Hernandez-Diaz S, Rodriguez LA. Association between nonsteroidal anti-inflammatory drugs and upper gastrointestinal tract bleeding/perforation: an overview of epidemiologic studies published in the 1990s. Arch. Intern. Med. 160(14), 2093-9 (2000).

22. Hansen JM, Hallas J, Lauritsen JM et al. Non-steroidal anti-inflammatory drugs and ulcer complications: a risk factor analysis for clinical decision-making. Scand. J. Gastroenterol. 31(2), 126-30 (1996).

23. Masclee GM, Valkhoff VE, Coloma PM et al. Risk of upper gastrointestinal bleeding from different drug combinations. Gastroenterology. 147(4), 784-92 (2014).

24. Rafaniello C, Ferrajolo C, Sullo MG et al. Risk of gastrointestinal complications associated to NSAIDs, low-dose aspirin and their combinations: Results of a pharmacovigilance reporting system. Pharmacol. Res. 104, 108-14 (2016).

25. Johnsen SP, Sørensen HT, Mellemkjoer L et al. Hospitalisation for upper gastrointestinal bleeding associated with use of oral anticoagulants. Thromb. Haemost. 86(2), 563-8 (2001).

26. Lanas A, García-Rodríguez LA, Arroyo MT et al. Effect of antisecretory drugs and nitrates on the risk of ulcer bleeding associated with nonsteroidal anti-inflammatory drugs, antiplatelet agents, and anticoagulants. Am. J. Gastroenterol. 102(3), 507-15 (2007).
27. Penning-van Beest F, Erkens J, Petersen KU et al. Main comedications associated with major bleeding during anticoagulant therapy with coumarins. Eur. J. Clin. Pharmacol. 61(5-6), 439-44 (2005).

28. Garcia Rodriguez LA, Hernandez-Diaz S. The risk of upper gastrointestinal complications associated with nonsteroidal anti-inflammatory drugs, glucocorticoids, acetaminophen, and combinations of these agents. Arthritis. Res. 3(2), 98-101 (2001).

29. Masclee GM, Valkhoff VE, van Soest EM et al. Cyclooxygenase-2 inhibitors or nonselective NSAIDs plus gastroprotective agents: what to prescribe in daily clinica practice? Aliment. Pharmacol. Ther. 38(2), 178-89 (2013).

30. Sostres C, Carrera-Lasfuentes P, Benito R et al. Peptic Ulcer Bleeding Risk. The Role of Helicobacter Pylori Infection in NSAID/Low-Dose Aspirin Users. Am. J. Gastroenterol. 110(5), 684-9 (2015).

31. Garcia Rodriguez LA, Barreales Tolosa L. Risk of upper gastrointestinal complications among users of traditiona NSAIDs and COXIBs in the general population Gastroenterology. 132(2), 498-506 (2007).

32. Rostom A, Muir K, Dube C et al. Prevention of NSAIDrelated upper gastrointestinal toxicity: a meta-analysis of traditional NSAIDs with gastroprotection and COX-2 inhibitors. Drug. Health. Patient. Saf. 1, 47-71 (2009).

33. Mahadeva S, Yadav H, Everett SM et al. Economic impact of dyspepsia in rural and urban malaysia: a population-based study. J. Neurogastroenterol. Motil. 18(1), 43-57 (2012).

34. Schnitzer TJ, Burmester GR, Mysler E et al. Comparison of lumiracoxib with naproxen and ibuprofen in the Therapeutic Arthritis Research and Gastrointestinal Event Trial (TARGET), reduction in ulcer complications: randomised controlled trial. Lancet. 364(9435), 665-74 (2004).

35. Singh G, Fort JG, Goldstein JL et al. Celecoxib versus naproxen and diclofenac in osteoarthritis patients: SUCCESS-I Study. Am. J. Med. 119(3), 255-66 (2006).

36. Regula J, Butruk E, Dekkers CP et al. Prevention of NSAID-associated gastrointestinal lesions: a comparison study pantoprazole versus omeprazole. Am. J. Gastroenterol. 101(8), 1747-55 (2006).

37. Yu CP, Whynes DK, Sach TH. Equity in health care financing: The case of Malaysia. Int. J. Equity. Health. 7, 15 (2008).

38. Bathon JTC, Klippel SJ, Crofford LJ et al. Rheumatoid arthritis clinical and laboratory manifestations, (2008). 